\title{
Stable-Isotope Dilution Analysis of D- and L-2-Hydroxyglutaric Acid: Application to the Detection and Prenatal Diagnosis of $\mathrm{D}-$ and L-2-Hydroxyglutaric Acidemias
}

\author{
K. M. GIBSON', H. J. TEN BRINK, D. S. M. SCHOR, R. M. KOK, A. H. BOOTSMA,
} G. F. HOFFMANN, AND C. JAKOBS

Department of Pediatrics, Free University Hospital, Amsterdam, The Netherlands [K.M.G., H.J.T.B., D.S.M.S., R.M.K., A.H.B., C.J.J, and Department of Pediatrics, University of Heidelberg, Germany/G.F.H.J

\begin{abstract}
A stable-isotope dilution assay has been developed for quantitation of $\mathrm{D}$ - and L-2-hydroxyglutaric acids in physiologic fluids. D- and L-2-hydroxyglutaric acids are separated as the $\mathrm{O}$-acetyl-di-(D)-2-butyl esters. The method uses $D, L-\left[3,3,4,4-{ }^{2} \mathrm{H}_{4}\right]-2$-hydroxyglutaric acid as internal standard with ammonia chemical ionization, selected ion monitoring gas chromatography-mass spectrometry. For 13 patients with L-2-hydroxyglutaric aciduria, the concentrations of L-2-hydroxyglutaric acid were urine, $1283 \pm 676 \mathrm{mmol} / \mathrm{mol}$ creatinine (range, 332-2742; $n=12$ patients); plasma, $47 \pm 13 \mu \mathrm{mol} / \mathrm{L}$ (range, 27-62; $n=8$ ); cerebrospinal fluid, $62 \pm 30 \mu \mathrm{mol} / \mathrm{L}$ (range, 34$100 ; n=6$ ). In a child with D-2-hydroxyglutaric aciduria, the levels of D-2-hydroxyglutaric acid were urine, $1565 \pm$ $847 \mathrm{mmol} / \mathrm{mol}$ creatinine (range, $729-2668 ; n=4$ ); plasma, $61 \pm 14 \mu \mathrm{mol} / \mathrm{L}$ (range, 46-73; $n=3$ ); cerebrospinal fluid, 15 and $25 \mu \mathrm{mol} / \mathrm{L}(n=2)$. Control concentrations of $\mathrm{D}-$ and L-2-hydroxyglutaric acids were $(\mathrm{D}: \mathrm{L})$ : urine $(n=18)$, $6.0 \pm 3.6 \mathrm{mmol} / \mathrm{mol}$ creatinine (range, $2.8-17): 6.0 \pm 5.4$ (range, 1.3-19); plasma $(n=10), 0.7 \pm 0.2 \mu \mathrm{mol} / \mathrm{L}$ (range, $0.3-0.9$ ): $0.6 \pm 0.2$ (range, $0.5-1.0$ ); cerebrospinal fluid $(n=10), 0.1 \pm 0.1 \mu \mathrm{mol} / \mathrm{L}$ (range, 0.07-0.3): $0.7 \pm 0.6$ (range, 0.3-2.3). Investigation of control amniotic fluid $(n=10)$ revealed the following values (D:L): $1.2 \pm 0.4$ $\mu \mathrm{mol} / \mathrm{L}$ (range, 0.6-1.8): $4.0 \pm 0.7$ (range, 3.1-5.2), suggesting the feasibility of prenatal diagnosis in families at risk. (Pediatr Res 34: 277-280, 1993)
\end{abstract}

\section{Abbreviations}

2-HG, 2-hydroxyglutaric CSF, cerebrospinal fluid

GC-MS, gas chromatography-mass spectrometry TMS, trimethylsilyl

2-HG acid is detected in normal human urine and is elevated in the urine of patients with multiple acyl-CoA dehydrogenase deficiency (glutaric aciduria type II) (1). Despite its occurrence in $\mathrm{D}$ and $\mathrm{L}$ configurations, there has been no systematic investi-

Received January 26, 1993; accepted April 14, 1993.

Correspondence and reprint requests: K. M. Gibson, Ph.D., Baylor Research Institute, 3812 Elm St., Dallas, TX 75226.

Supported by Grant 966/3-2 from the Deutsche Forschungsgemeinschaft (G.F.H.) and a Fellowship from the Alexander von Humboldt Foundation of Germany (K.M.G.).

K.M.G. is on leave from the Kimberly H. Courtwright and Joseph W. Summers Metabolic Disease Center and Baylor Research Institute, Dallas, TX. gation on the concentrations of D- and L-2-HG acids in human physiologic fluids. The separation of D-and $\mathrm{L}-2-\mathrm{HG}$ acid requires the expensive preparation of chiral derivatives using (D)-2-butanol, which may account for the lack of detailed analyses of the different configurations in humans $(2,3)$.

Since the description of the index patients with D- and L-2$\mathrm{HG}$ aciduria $(2,3)$, a number of patients with $2-\mathrm{HG}$ aciduria have been reported. Barth et al. (4) reported eight patients with cerebellar dysfunction, extrapyramidal signs, mental regression, and seizure disorders. Magnetic resonance imaging findings suggested a spongiform leukodystrophy. L-2-HG acid concentration was elevated in urine, plasma, and CSF without additional organic aciduria (5). A patient with D-2-HG aciduria manifested a protein-losing enteropathy and normal cognitive development (3). D-2-HG aciduria was reported in another patient who manifested an early-onset, severe seizure disorder with hypotonia and cortical blindness (6). In this patient, D-2-HG acid was increased in urine, plasma, and CSF; conversely, in the patient described by Chalmers et al. (3), D-2-HG acid was not elevated in blood, and CSF was not investigated. Haworth et al. (7) detected 2-HG aciduria in a growth-retarded newborn female with dysmorphic facial features, hepatosplenomegaly, and tricuspid regurgitation, but there was no indication of which isomer was excreted.

The existence of isolated diseases in which D- and L-2-HG acids accumulate suggests the need for an accurate method for quantitation of these metabolites in human physiologic fluids. We have developed a sensitive stable-isotope dilution assay for quantitation of D- and L-2-HG acids using ammonia chemical ionization, combined with GC-MS. Using this procedure, we quantitated the concentrations of $\mathrm{D}$ - and $\mathrm{L}-2-\mathrm{HG}$ acids in urine, plasma, and CSF from controls, 13 patients with L-2-HG aciduria, and one patient with D-2-HG aciduria. To facilitate eventual prenatal diagnosis of these disorders, concentrations of D- and L2-HG acids were determined in control amniotic fluid. This report describes the procedures and summarizes the results of these investigations.

\section{MATERIALS AND METHODS}

Patients. Clinical details on eight of 13 L-2-HG aciduria patients whom we investigated and on the D-2-HG aciduria patient have been reported $(4-6,8)$. An additional five patients with L$2-\mathrm{HG}$ aciduria have not been reported. The presentation in a $12-$ y-old boy included mental retardation, seizures, pyramidal signs, brain atrophy, and calcification of the frontal lobe. Clinical evaluation of a 20 -year-old male at 6 y revealed mental retardation (IQ 60), cerebellar ataxia, unsteadiness, dysarthria, macrocephaly, scoliosis, seizures, and head tremor. CSF lysine concentration was elevated with normal plasma lysine levels. His sister 

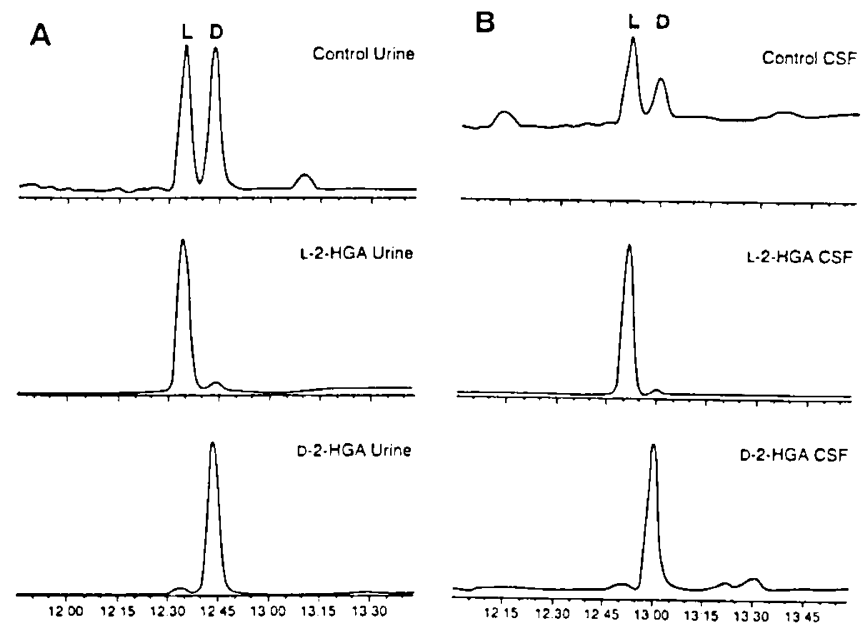

Fig. 1. Mass fragmentograms (m/z 303) of $D-$ and L-2-hydroxyglutaric acids in urine $(A)$ and CSF $(B)$ as the (D and L)-O-acetyl-2-HG acid di-(D)-2-butyl esters. Top, control; middle, a patient with L-2-hydroxyglutaric aciduria; bottom, a patient with D-2-hydroxyglutaric aciduria. Peak heights are normalized to full-scale deflection. For figure clarity, $\mathrm{m} / \mathrm{z}$ 307 was omitted.

was clinically unaffected. Computed tomography and magnetic resonance imaging revealed ventricular enlargement, cortical atrophy, and subcortical white matter lesions. Two other patients, male and female siblings of Tunisian descent, died at 30 and 6 y of age, respectively (Dr. P. G. Barth, personal communication). Complete clinical details will be presented elsewhere. The remaining patient was a 21 -y-old female for whom clinical details were unavailable.

Synthesis of internal standard. D, L- $\left[3,3,4,4-{ }^{2} \mathrm{H}_{4}\right]-2-\mathrm{HG}$ acid (zinc salt) was prepared by reduction of commercially available $\left[{ }^{2} \mathrm{H}_{4}\right]-2-$ oxoglutaric acid by reaction with excess zinc. To a stirred suspension of zinc powder $(0.12 \mathrm{~g})$ in ice-cold water $(1 \mathrm{~mL})$, a solution of $\left[3,3,4,4-{ }^{2} \mathrm{H}_{4}\right]-2-0 x o g l u t a r i c$ acid $(0.15 \mathrm{~g}, 98.7$ atom percent ${ }^{2} \mathrm{H}$, Merck Sharp \& Dohme, Montreal, Canada) in icecold water $(0.5 \mathrm{~mL})$ was slowly added. After stirring the cooled mixture for $30 \mathrm{~min}$, a light precipitate was formed. Excess zinc was separated by centrifuging for $2 \mathrm{~min}$ at $600 \mathrm{rpm}$ and removal of the turbid water phase. The zinc residue was repeatedly washed with water ( $1-\mathrm{mL}$ portions) and centrifuged until the water phase was clear. The product was further precipitated by adding three volumes of acetone to the combined water phases. After centrifuging for $5 \mathrm{~min}$ at $2000 \mathrm{rpm}$ and removal of the solution, the product was washed twice with acetone $(10 \mathrm{~mL})$ and dried under a stream of nitrogen yielding a white powder $(0.18 \mathrm{~g}, 85 \%$ yield). The tri-TMS derivative was pure by gas chromatography, $\mathrm{D}$ and $L$ isomers were present in equal amounts (for separation conditions, see below), and isotopic purity was $>98$ atom $\%{ }^{2} \mathrm{H}$.

Derivatization. D- and L-2-HG acids in physiologic fluids were separated as the (D and L)-O-acetyl-2-HG acid di-(D)-2-butyl esters (2). Standards (D- and L-2-HG acids, Sigma Chemical Co., St. Louis, MO) or samples (0.1-0.5 mL, or appropriate dilution of patient specimens) received $20 \mathrm{nmol} \mathrm{D,L-}\left[3,3,4,4-{ }^{2} \mathrm{H}_{4}\right]-2-\mathrm{HG}$ acid. After volume adjustment to $1 \mathrm{~mL}$, samples were acidified to $\mathrm{pH} 1-2$ with $6 \mathrm{~N} \mathrm{HCl}$ and extracted three times with $4 \mathrm{~mL}$ of ethyl acetate. The solvent fractions were pooled, dried over sodium sulfate, and taken to dryness under a gentle stream of nitrogen. Initially, tri-TMS derivatives of $2-\mathrm{HG}$ acid were made according to established methods (1). Butylation was achieved by addition of $0.5 \mathrm{~mL}$ (D)-2-butanol (Fluka, Munich, Germany) and $0.05 \mathrm{~mL} 12 \mathrm{~N} \mathrm{HCl}$ to the residue, and the samples were heated for $3 \mathrm{~h}$ at $90^{\circ} \mathrm{C}$. After cooling, samples were twice extracted with $4 \mathrm{~mL}$ of hexane, dried over sodium sulfate, and the solvent evaporated under nitrogen. For acetylation, $0.3 \mathrm{~mL}$ of pyridine and $0.3 \mathrm{~mL}$ of acetic anhydride were added to the residue with heating for $1 \mathrm{~h}$ at $80^{\circ} \mathrm{C}$. After evaporation, the residues were
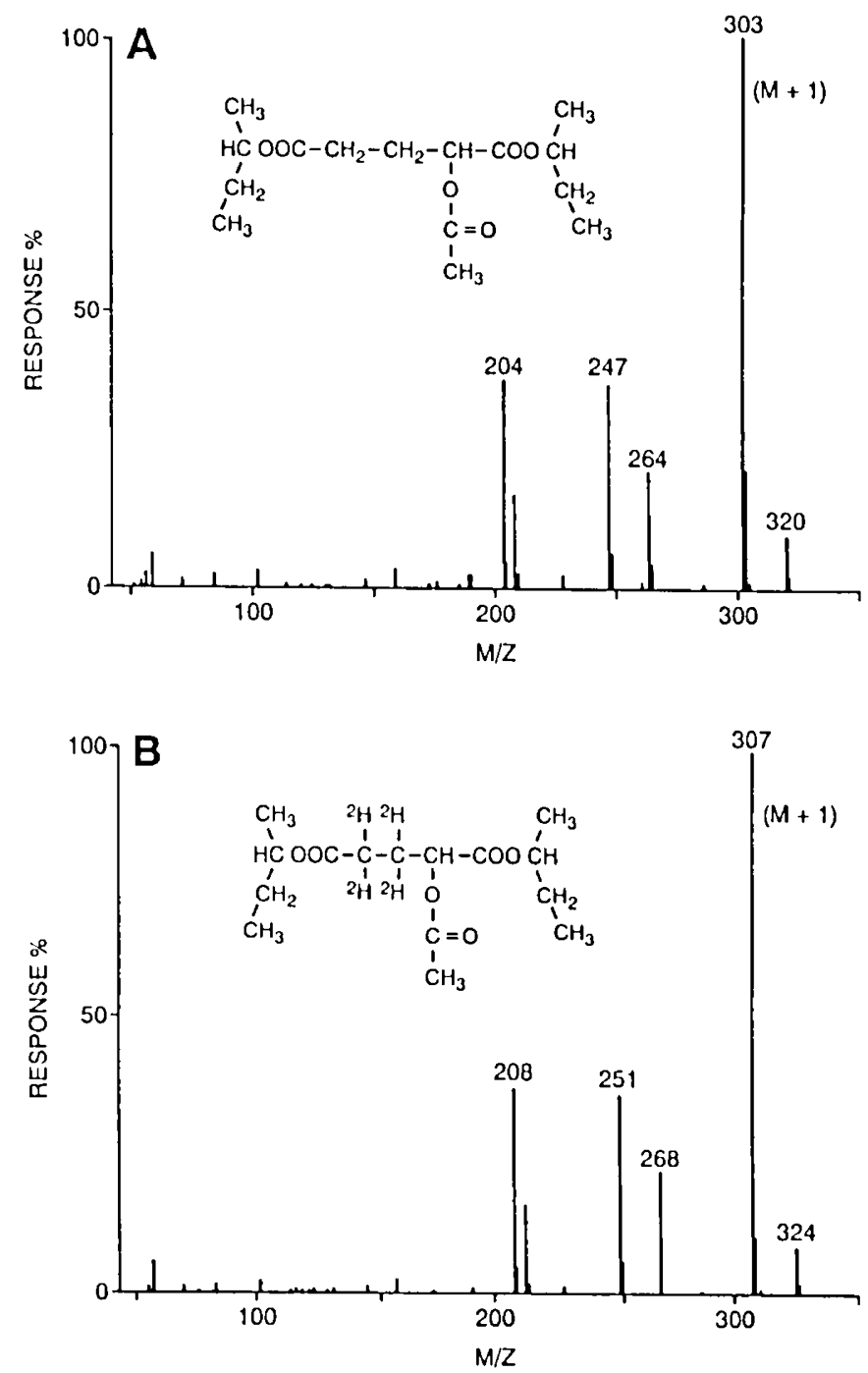

Fig. 2. Ammonia chemical ionization mass spectra of $(A)\left[{ }^{2} \mathrm{H}_{0}\right]-2$ hydroxyglutaric acid and $(B)\left[{ }^{2} \mathrm{H}_{4}\right]-2$-hydroxyglutaric acid recorded as the O-acetyl-di-(D)-2-butyl esters. Selected-ion monitoring was performed at $\mathrm{m} / \mathrm{z} 303$ and $\mathrm{m} / \mathrm{z} 307$.

redissolved in $0.1 \mathrm{~mL}$ of chloroform in preparation for GC-MS analysis.

$G C-M S$. Gas chromatographic separation was achieved on a CP Sil 88 fused silica capillary column (Chrompack, Middelburg, The Netherlands), $25 \mathrm{~m} \times 0.32 \mathrm{~mm}$ inner diameter, film thickness $0.2 \mathrm{~mm}$, which was directly inserted into the ion source of the mass spectrometer. Helium was used as carrier gas with a flow rate of $30 \mathrm{~cm} / \mathrm{s}$. The column oven was maintained for 3 min at $120^{\circ} \mathrm{C}$, then programmed to $175^{\circ} \mathrm{C}$ at a rate of $4^{\circ} \mathrm{C} / \mathrm{min}$ and finally programmed to $220^{\circ} \mathrm{C}$ at a rate of $20^{\circ} \mathrm{C} / \mathrm{min}$. The samples were introduced using a solid injector (glass falling needle) operated at $300^{\circ} \mathrm{C}$.

GC-MS analysis was performed on a Kratos MS-80 instrument (Kratos Ltd., Manchester, UK) in the positive chemical ionization mode. The chemical ionization reagent gas was ammonia. Ionization was initiated with $50 \mathrm{eV}$ electrons with an emission current of $1.5 \mathrm{~mA}$. The source temperature was $230^{\circ} \mathrm{C}$. Selected ion monitoring for quantitation was performed by recording the ions at $\mathrm{m} / \mathrm{z} 303$ for $2-\mathrm{HG}$ acid and 307 for the $\left[{ }^{2} \mathrm{H}_{4}\right]-2-\mathrm{HG}$ acid analogue. The dwell time was $50 \mathrm{~ms}$, and the resolution was 1000 (10\% valley). All areas of the mass-spectrometric peaks were integrated using the computer with operator selection of the baseline points. Aqueous standard solutions containing 20 $\mathrm{nmol}$ of the internal standard $\mathrm{D}, \mathrm{L}-\left[{ }^{2} \mathrm{H}_{4}\right]-2-\mathrm{HG}$ acid and variable amounts (1-30 nmol) of D- or L-2-HG acid were prepared and 
Table 1. D- and L-2-HG acid concentrations in physiologic fluids from controls and patients determined by stable-isotope dilution assay as $O$-acetyl-Diz(D)-2-butyl esters*

\begin{tabular}{|c|c|c|c|}
\hline Subject & Body fluid & D Isomer & L Isomer \\
\hline \multirow[t]{4}{*}{ Controls } & Urine $(n=18)($ age $10 \mathrm{~d}-45 \mathrm{y})$ & $\begin{array}{l}6.0 \pm 3.6 \\
(2.8-17)\end{array}$ & $\begin{array}{l}6.0 \pm 5.4 \\
(1.3-19)\end{array}$ \\
\hline & Plasma $(n=10)($ age $1-60 \mathrm{y})$ & $\begin{array}{l}0.7 \pm 0.2 \\
(0.3-0.9)\end{array}$ & $\begin{array}{l}0.6 \pm 0.2 \\
(0.5-1.0)\end{array}$ \\
\hline & $\operatorname{CSF}(n=10)($ age $2 \mathrm{mo}-41 \mathrm{y})$ & $\begin{array}{r}0.1 \pm 0.1 \\
(0.07-0.3)\end{array}$ & $\begin{array}{l}0.7 \pm 0.6 \\
(0.3-2.3)\end{array}$ \\
\hline & Amniotic fluid $(n=10)$ & $\begin{array}{l}1.2 \pm 0.4 \\
(0.6-1.8)\end{array}$ & $\begin{array}{l}4.0 \pm 0.7 \\
(3.1-5.2)\end{array}$ \\
\hline \multirow[t]{3}{*}{ L-2-HG aciduria patients } & Urine $(n=9)($ age $9-39 \mathrm{y})$ & $\begin{array}{l}12 \pm 5.9 \\
(4.1-22)\end{array}$ & $\begin{array}{c}1283 \pm 676 \\
(332-2742)\end{array}$ \\
\hline & Plasma $(n=8)$ & $\begin{array}{l}0.8 \pm 0.4 \\
(0.3-1.3)\end{array}$ & $\begin{array}{l}47 \pm 13 \\
(27-62)\end{array}$ \\
\hline & $\operatorname{CSF}(n=6)$ & $\begin{array}{l}0.4 \pm 0.2 \\
(0.2-0.6)\end{array}$ & $\begin{array}{l}62 \pm 30 \\
(34-100)\end{array}$ \\
\hline \multirow[t]{3}{*}{ D-2-HG aciduria patient $\dagger$} & Urine (age $3 \mathrm{mo}$ ) & $\begin{array}{l}1565 \pm 847 \\
\quad(729-2668)\end{array}$ & $\begin{array}{l}12 \pm 4.4 \\
(7.5-16)\end{array}$ \\
\hline & Plasma & $\begin{array}{l}61 \pm 14 \\
(46-73)\end{array}$ & $\begin{array}{l}1.0 \pm 0.7 \\
(0.3-1.7)\end{array}$ \\
\hline & CSF & 15,25 & $0.4,0.6$ \\
\hline
\end{tabular}

* Amniotic fluid specimens were obtained at $16-18 \mathrm{wk}$ gestation. Units: urine, $\mathrm{mmol} / \mathrm{mol}$ creatinine; plasma, CSF, and amniotic fluid, $\mu \mathrm{mol} / \mathrm{L}$. Data are presented as mean $\pm 1 \mathrm{SD}$, with range in parentheses; $n$ values represent the number of individuals studied.

† Four samples of urine, three samples of plasma, and two CSF samples were available.

Table 2. Total 2-HG acid concentration in physiologic fluids from controls and patients determined by stable-isotope dilution assay as Tri-TMS esters*

\begin{tabular}{lcc}
\hline \multicolumn{1}{c}{ Subject } & Body fluid & 2-HG acid \\
\hline Controls & Urine $(n=31)$ (age & $14.2 \pm 11.3$ \\
& newborn-30 y) & $(1.6-40)$ \\
& Plasma $(n=8)$ (age 3 & $1.9 \pm 0.4$ \\
mo-53 y) & $(1.5-2.5)$ \\
& CSF $(n=5)$ (age 3 mo- & $1.9 \pm 0.2$ \\
& 4 y) & $(1.8-2.4)$ \\
& Amniotic fluid ( $n=15)$ & $4.2 \pm 1.4$ \\
& & $(1.8-6.5)$ \\
L-2-HG aciduria patients & Urine $(n=6)$ (age 9-39 & $1594 \pm 920$ \\
& y) & $(810-4210)$ \\
& Plasma $(n=5)$ & $35 \pm 11$ \\
& & $(16-46)$ \\
& $C S F(n=3)$ & $38 \pm 14$ \\
& & $(23-49)$ \\
\hline
\end{tabular}

* Amniotic fluid specimens were obtained at $16-18$ wk gestation. Units: urine, $\mathrm{mmol} / \mathrm{mol}$ creatinine; plasma, CSF, and amniotic fluid, $\mu \mathrm{mol} / \mathrm{L}$. Data are presented as mean $\pm 1 \mathrm{SD}$, with range in parentheses $n$ values represent the number of individuals studied. Body fluids from the D-2-HG aciduria patient were not investigated as the tri-TMS esters.

carried through the entire procedure to establish calibration curves. Linear regression analysis was used to calculate metabolite concentrations in physiologic fluids.

\section{RESULTS}

D- and L-2-HG acid, as the O-acetyl-di-(D)-2-butyl esters, could be distinguished on gas chromatographic analysis with nearbaseline separation, and patients with D- or L-2-HG aciduria could readily be identified (Fig. 1). Calibration curves yielded straight lines that went through the origin $(r>0.995, n=10)$. Selected ion monitoring at $\mathrm{m} / \mathrm{z} 303$ and 307 for the $[\mathrm{M}+\mathrm{H}]^{+}$ for ${ }^{2} \mathrm{H}_{0}$ and ${ }^{2} \mathrm{H}_{4}$ analogues, respectively, allowed accurate quantitation of the concentration of each metabolite in the different body fluids investigated (Fig. 2). The absence of fragments at $\mathrm{m} / \mathrm{z}$ 303-306 (Fig. $2 B$ ) verified that sample preparation and heating in the injector at $300^{\circ} \mathrm{C}$ did not lead to deuterium exchange. In control body fluids (Table 1), urine and plasma contained nearly equal amounts of D- and L-2-HG acids, whereas the ratio of $\mathrm{L}-$ to $\mathrm{D}-2-\mathrm{HG}$ acid was higher in CSF.

For L-2-HG aciduria patients, there was a relatively consistent increase of $\mathrm{L}-2-\mathrm{HG}$ acid in comparison to controls for all physiologic fluids studied, from 80-200-fold, without significant increase in excretion of the $\mathrm{D}$ isomer. In patients with $\mathrm{L}-2-\mathrm{HG}$ aciduria, we detected nearly equal concentrations of the L-isomer in plasma and in CSF, whereas Barth et al. (4) suggested an increased ratio of the $\mathrm{L}$ isomer between CSF and plasma. In physiologic fluids obtained from first-degree relatives of the two sets of male siblings with L-2-HG aciduria whom we investigated, normal concentrations of $\mathrm{D}-$ and $\mathrm{L}-2-\mathrm{HG}$ acids were detected (data not shown). In a patient with $\mathrm{D}-2-\mathrm{HG}$ aciduria, the range of increase of $\mathrm{D}-2-\mathrm{HG}$ acid in physiologic fluids in comparison to control (i.e. comparison of mean to mean) was approximately 90-260-fold, with the largest increase in the urine. As for the L2-HG aciduria patients, no increase in the $\mathrm{D}$ or $\mathrm{L}$ isomer of 2 HG acid was detected in urine from parents of the D-2-HG aciduria patient. To establish reference values for the potential prenatal diagnosis of both $\mathrm{D}$ - and $\mathrm{L}-2-\mathrm{HG}$ aciduria, control amniotic fluid was investigated for the concentration of $D-$ and L-2-HG acids. In 10 amniotic fluids, we detected $\mathrm{D}$ isomer, $1.2 \pm 0.4 \mu \mathrm{mol} / \mathrm{L}$ (mean $\pm 1 \mathrm{SD}$, range $0.6-1.8$ ) and $\mathrm{L}$ isomer, $4.0 \pm 0.7 \mu \mathrm{mol} / \mathrm{L}$ (range, 3.1-5.2).

In preliminary investigations, we attempted to separate and quantify $\mathrm{D}$ - and L-2-HG acids as the tri-TMS derivatives using the tetradeuterated internal standard. Although accurate quantitation was achieved (Table 2), separation of the $\mathrm{D}$ and $\mathrm{L}$ isomers was not possible. Comparison of values generated using the two derivatives (Tables 1 and 2) demonstrates relatively good agreement between the two for controls and patients with $\mathrm{L}-2-\mathrm{HG}$ aciduria. One notable difference is the somewhat higher estimation of total 2-HG acid concentration in control CSF using the tri-TMS derivative as compared with the O-acetyl-di-(D)-2-butyl ester analogues (Tables 1 and 2). As the tri-TMS ester derivatives, the amniotic fluid concentration of $2-\mathrm{HG}$ acid $(n=15)$ was $4.2 \pm 1.4 \mu \mathrm{mol} / \mathrm{L}$ (range, $1.8-6.5$ ), which was comparable to individual values obtained for D- and L-2-HG acids analyzed as the O-acetyl-di-(D)-2-butyl esters. This indicates that with the stable-isotope dilution method using tetradeuterated internal standard, it should be possible to perform prenatal diagnosis for either D- or L-2-HG aciduria using tri-TMS derivatives. 


\section{DISCUSSION}

This method for separation and quantitation of D- and L-2$\mathrm{HG}$ acid in physiologic fluids is sensitive and accurate and for the first time provides accurate values, including control values. The use of stable-isotope dilution assay should facilitate the prenatal diagnosis of both disorders. Although L-2-HG aciduria appears to be a defined Mendelian disorder, additional patients with $\mathrm{D}-2-\mathrm{HG}$ aciduria will need to be characterized to define the phenotype and the inheritance of that disorder. It is of interest that the original patient with D-2-HG aciduria (3) had no neurologic abnormalities. This raises the possibility that D-2-HG acid is unrelated to neurologic findings in the patient with D-2HG aciduria whom we investigated. However, D-2-HG acid was not increased in blood, and CSF was not studied in the patient reported by Chalmers $e t$ al. (3). In the D-2-HG aciduria patient whom we investigated, the increase of CSF D-2-HG acid, in comparison to the control mean value, was elevated 200 -fold, raising the possibility that $\mathrm{D}-2-\mathrm{HG}$ acid may be at least partially produced in neural tissue.

This is the first study in which body fluids from most available patients with D- and L-2-HG aciduria have been studied in one laboratory using a uniform, standardized method. Little is known about the role of $\mathrm{D}$ - and $\mathrm{L}-2-\mathrm{HG}$ acids in mammalian metabolism. In patients with multiple acyl-CoA dehydrogenase deficiency, 2-HG acid is a characteristic and highly elevated urinary metabolite, and the isomer predominantly excreted has the D configuration (9). This raises the possibility that one source of D2-HG acid may be the mitochondrial electron transport chain. For D-2-HG acid, two mammalian pathways have been described that metabolize this compound (6). In one D-2-HG acid is converted to 2-ketoglutaric acid by $\mathrm{D}-2-\mathrm{HG}$ acid dehydrogenase in the pathway of 5-aminolevulinic acid metabolism. In the second pathway, D-2-HG acid is converted to 2-ketoglutaric acid by a transhydrogenase that uses succinic semialdehyde as hydrogen acceptor (10). This reaction is nicotinamide-independent and has not been described in human tissues. The possibility that one of these reactions is abnormal in our patient with D-2HG aciduria has not yet been explored. In those inborn errors of metabolism in which 5-aminolevulinic acid and succinic semialdehyde accumulate, including acute intermittent porphyria, tyrosinemia type I, and succinic semialdehyde dehydrogenase deficiency, 2-HG acid concentration is not elevated in urine.

Other pathways involved in the metabolism of D-2-HG acid are mainly bacterial (6), and little is known about the precursors of D-2-HG acid. Similarly, even less is known about the precursors and metabolites of $\mathrm{L}-2-\mathrm{HG}$ acid (4). In the eight patients described, Barth et al. (4) found elevations in plasma and CSF L-lysine concentrations, but oral loading with L-lysine in three L2-HG aciduria patients did not result in enhanced $\mathrm{L}-2-\mathrm{HG}$ acid excretion. Plasma lysine concentration was normal in the patient with D-2-HG aciduria. In both disorders, pipecolic acid concen- trations in physiologic fluids was normal, arguing against disordered lysine metabolism.

Eventually, it will be necessary to undertake studies of the metabolism of D- and L-2-HG acids in animal systems, either in vivo or in isolated organs, tissue homogenates or both. To this end, the use of stable isotope precursors, as described in this report, will be of value in determining metabolic routes. The report and characterization of additional patients, with accurate screening of body fluids for organic and amino acids, may provide insights into the physiologic precursors of both $\mathrm{D}$ - and L-2-HG acids. At present, there is no information on the concentration of D- and L-2-HG acids in mammalian tissues, and the ratio of isomers in neural and non-neural tissues is undefined. Investigation of the quantities of D- and L-2-HG acids in different mammalian tissues will provide a basis from which to decide which tissue may be optimal for metabolic studies. Studies on the normal metabolism of D- and $\mathrm{L}-2-\mathrm{HG}$ acids may provide insights into the primary defect in patients with specific D- and $\mathrm{L}-2-\mathrm{HG}$ aciduria.

Acknowledgments. The authors thank the following investigators who supplied specimens from patients: J. Jaeken, F. Hanefeld, F. K. Trefz, H.-P. Hartung, W. Lehnert, P.G. Barth, P. Divry, D. Rabier, G. Herman, W. Craigen, and E. Christensen.

\section{REFERENCES}

1. Sweetman L 1991 Organic acid analysis. In: Hommes FA (ed) Techniques in Diagnostic Human Biochemical Genetics. Wiley-Liss, New York, pp 143176

2. Duran M, Kamerling JP, Bakker HD, van Gennip AH, Wadman SK 1980 L2-Hydroxyglutaric aciduria: an inborn error of metabolism? J Inherit Metab Dis 3:109-112

3. Chalmers RA, Lawson AM, Watts RWE. Tavill AS, Kamerling JP, Hey E, Ogilvie D 1980 D-2-Hydroxyglutaric aciduria: case report and biochemical studies. J Inherit Metab Dis 3:11-15

4. Barth PG, Hoffmann GF, Jaeken J, Lehnert W, Hanefeld F, van Gennip AH, Duran M, Valk J, Schutgens RBH, Trefz FK, Reimann G, Hartung H-P 1992 L-2-Hydroxyglutaric acidemia: a novel inherited neurometabolic disease. Ann Neurol 32:66-71

5. Barth PG, Hoffmann GF, Jaeken J, Wanders RJA, Duran M, Jansen GA, Jakobs C, Lehnert W, Hanefeld F, Valk J, Schutgens RBH, Trefz FK, Hartung H-P, Chamoless NA, Caruso U 1993 L-2-Hydroxyglutaric acidemia: clinical and biochemical findings in 12 patients and preliminary report on L-2-hydroxy acid dehydrogenase. J Inherit Metab Dis (in press)

6. Gibson KM, Craigen W, Herman GE, Jakobs C 1993 D-2-Hydroxyglutaric aciduria in a newborn with neurologic abnormalities: a new neurometabolic disorder? J Inherit Metab Dis (in press)

7. Haworth JE, Dilling LA, Seargeant LE 1991 Increased prevalence of hereditary metabolic diseases among native Indians in Manitoba and northwestern Ontario. Can Med Assoc J 145:123-129

8. Divry P, Jakobs C, Vianey-Saban C, Michelakakis H, Gibson KM, Papadimitriou A, Divari R, Chabrol B. Cournelle MA, Livet MO 1993 L-2-Hydroxyglutaric aciduria: two further cases. J Inherit Metab Dis (in press)

9. Goodman SI, Reale M, Berlow S 1983 Glutaric acidemia type II: a form with deleterious intrauterine effects. J Pediatr 102:411-413

10. Kaufman EE, Nelson T, Fales HM, Levin DM 1988 Isolation and characterization of a hydroxyacid-oxoacid transhydrogenase from rat kidney mitochondria. J Biol Chem 263:16872-16879 